\title{
A Smart eCook Battery-Charging System to Maximize Electric Cooking Capacity on a Hybrid PV/Diesel Mini-Grid
}

\author{
Shafiqa Keddar *, Scott Strachan and Stuart Galloway
}

Citation: Keddar, S.; Strachan, S.; Galloway, S. A Smart eCook Battery-Charging System to Maximize Electric Cooking Capacity on a Hybrid PV/Diesel Mini-Grid. Sustainability 2022, 14, 1454. https:// doi.org/10.3390/su14031454

Academic Editors: Andrea Micangeli, Linda Barelli and Paolo Cherubini

Received: 16 December 2021

Accepted: 25 January 2022

Published: 27 January 2022

Publisher's Note: MDPI stays neutral with regard to jurisdictional claims in published maps and institutional affiliations.

Copyright: (C) 2022 by the authors. Licensee MDPI, Basel, Switzerland. This article is an open access article distributed under the terms and conditions of the Creative Commons Attribution (CC BY) license (https:// creativecommons.org/licenses/by/ $4.0 /)$.
Department of Electronic and Electrical Engineering, University of Strathclyde, Glasgow G1 1XQ, UK; scott.strachan@strath.ac.uk (S.S.); stuart.galloway@strath.ac.uk (S.G.)

* Correspondence: shafiqa.keddar@strath.ac.uk

\begin{abstract}
In this paper, eCook batteries are considered to be synonymous with those electric cooking devices (eCook), such as electric pressure cookers, induction cookers, hotplates or rice cookers, that can be connected to and supplied from a battery, which may or may not be fully integrated within the device. Connecting many eCook batteries can have an impact on the operation of a hybrid photovoltaic (PV)/diesel mini-grid network unless managed appropriately. The network could experience voltage fluctuations, system power losses and increased peak demand if all or most of the connected eCook batteries charge during a relatively "narrow" window of sunlight hours. Hence, this paper focuses on maximizing the number of eCook devices accommodated by the mini-grid, in keeping with increased consumer uptake, by regulating the charging rate (C-rate) of the eCook batteries themselves. The impact of varying the C-rate on the network constraints is assessed through a range of contextualized case studies. This entailed modeling an innovative smart eCook battery management system (EBMS) that actively monitors the state of the grid and decides on the eCook's battery C-rate set-point required to address the network constraints. The results demonstrate that the EBMS can alleviate the impact of conventional eCook battery charging on the mini-grid network, as well as increase the quality of the charging service.
\end{abstract}

Keywords: clean cooking; low- and middle-income countries; rural electrification; mini-grids; battery supported eCook; demand-side management

\section{Introduction}

Access to modern energy and clean cooking is a growing issue that is being widely addressed in developing countries. Around $40 \%$ of the world's population does not have access to clean cooking facilities, equating to 2.6 billion people globally $[1,2]$. Without accelerated remedial action, an estimated 2.4 billion people will still be without clean cooking services in 2030. The situation is particularly dire in sub-Saharan Africa and East Asia, where they still use traditional fuels, including wood, coal, straw, dung and charcoal for cooking. By continuing to use simple/traditional stoves (without a chimney or gate) such as a three-stone stove, high levels of household $(\mathrm{HH})$ air pollution cause severe health problems. Those who are most affected are those most exposed to these fumes, i.e., women and children. The World Health Organization (WHO) estimates that four million premature deaths occur annually, worldwide [2], as a result of respiration illnesses, heart disease and cancer, which have been attributed to the inhalation of particulates caused by indoor cooking. Greenhouse gas (GHG) emissions from cooking with traditional fuels can reach a gigaton of $\mathrm{CO}_{2}$ per year, equivalent to about $2 \%$ of global emissions [3,4], and as much as $25 \%$ of the black carbon emissions come from burning solid fuel for $\mathrm{HH}$ energy needs [5]. Up to 34\% [6] of the biomass fuel that is harvested is unsustainable, which has a profound effect on climate change due to the increasing rate of local forest degradation, leaving bare areas improperly treated after being cropped; this problem is particularly prevalent in the least developed countries. 
Several interventions regarding access to clean cooking have been adopted to address this issue through designing improved cookstoves (ICSs), aiming to reduce GHG emissions and improve public health [7]. However, their uptake has been limited and health problems often persist [8]. Therefore, if the health impact is to be further reduced, increased effort is required to enhance the efficiency of these ICS appliances, or another solution would be to move toward using electrical cooking appliances (or eCook, as referenced in this paper). The health and environmental benefits of replacing these traditional cooking fuels with eCook are stark, although implementing this transition represents significant technical and economic challenges.

Previous work related to this research [9] has shaped a methodology that could be used by mini-grid developers to assess the design readiness and future design requirement to enable usage without supported batteries. This allows an analytical investigation of mini-grid limitations. The findings show that the voltage drop and voltage imbalance (VUF) issues can be reasonably and affordably addressed by the use of cables of a slightly larger cross-sectional area (CSA). The main barrier lies in the shortfall of generation capacity and the cost of energy, which remains high even when upgrading the system. This supports the argument that there is merit in simulating the potential role and impact of demand-side management (DSM) in maximizing eCook while minimizing the upgrading of generation capacity. DSM strategies and different technologies are already being implemented in mini-grids to manage their operation, in order to accommodate more demand as customer behavior and energy requirements change, as well as to deal with new customer connections, enabling more efficient use of power systems [10]. However, there remains a need for more innovative and scalable techniques to facilitate the uptake of large power appliances such as eCook, while minimizing the need for capacity upgrades and network reinforcements.

The eCook-supported batteries (eCook batteries) represent a "flexible load" that can be used to maximize the utilization of electricity from the daily photovoltaic (PV) power and offset peak demand to different times of day, by charging the eCook batteries during off-peak hours in order to balance generation and demand. The main contribution of this paper is to provide an initial scoping study of both the challenges and opportunities when adopting eCook batteries, as well as developing an innovative smart eCook battery management system to maximize eCook demand within network constraints.

The remainder of this paper is organized as follows. In Section 2, outlines a literature review that was conducted to investigate the state of the art on DSM in developing countries, before determining the most appropriate approach and technology for "smart" eCook deployment on hybrid PV/diesel mini-grids. Section 3 presents the hybrid PV/diesel minigrid network model that forms the basis for both the simulation and the studies conducted in this paper. Section 4 highlights the technical limitations constraining the wide-scale deployment of eCook batteries. The proposed smart eCook battery charge management system approach and the simulation results are presented in Section 5. Section 6 evaluates the quality of charging service provided to HHs via eCook batteries. Section 7 provides a summary of our conclusions.

\section{Literature Review: Demand-Side Management}

\subsection{Current Use of DSM in the Mini-Grids of Developing Countries}

The DSM strategies and technologies used for rural mini-grids in developing countries (see Table 1) mostly target appliances that have more flexibility and do not affect $\mathrm{HH}$ comfort, and less research has been undertaken in exploring techniques to reduce the cooking peak load and inspire people to cook with electricity [11]. For example, DSM has been used to increase energy efficiency through reduced consumption in Zimbabwe [12], Ibadan (Nigeria) [13], and Bangladesh [14], where CFLs and incandescent bulbs were replaced with LEDs in domestic $\mathrm{HH}$ to explore the benefits of such a substitution. The impact of productive energy use during off-peak hours was studied in rural Bangladesh and Lake Victoria in Tanzania [15]; both projects allowed an increase in energy consumption 
when demand was low, which resulted in a positive impact on revenue. Energy metering and price incentives are other common approaches applied to mini-grids to reduce peak demand and shift to off-peak time. A project was rolled out in Senegal by ENERSA [15], where energy was sold in blocks to restrict energy and power consumption. The energy utilized was monitored using smart meters, which allowed HHs to plan and budget for their energy consumption. The subscription to the energy blocks lasted six months, which gave ENERSA a better insight into future demand.

Table 1. DSM strategies and technologies.

\begin{tabular}{cc}
\hline DSM Strategies & DSM Technologies \\
\hline Efficient appliances and lights & Current limiters \\
Commercial load scheduling \\
Restricting residential use \\
Price incentives & GridShare \\
Community involvement, consumer education, and village committees & $\begin{array}{c}\text { Conventional meters } \\
\text { Prepaid meters }\end{array}$ \\
& $\begin{array}{c}\text { Advanced metering systems with } \\
\text { centralized communication }\end{array}$ \\
\hline
\end{tabular}

However, the main research focus in this paper is on how to balance energy demand with generation to accommodate higher levels of cooking energy demand. Some authors have found that there is less willingness on behalf of the consumers to shift this type of load and that eCooks are the least favorite appliances used in DSM, due to their negative characteristics [16]. To capture such complex sets of interactions needs a broader perspective; this requires a sophisticated modeling framework to enable the transition toward eCook by exploring concepts for "smart" eCook devices.

As a starting point toward providing a useful foundation by which to build a smart eCook control management strategy, battery-supported eCooks are explored in this part of the research. They allow voids in supply to be filled, to offset demand and increase the revenue of the utility via charging the eCook batteries during off-peak periods so that they can be used when demand is high and there is insufficient PV production.

\section{2. eCook Battery-Charging Methods}

The choice of method for battery charging depends mainly on the type of battery and its application. Typical methods can be mainly classified into constant voltage (CV), constant current (CC), and a combination of CC-CV [17-19]. The first is frequently used with lead-acid batteries, as the method adopts a predefined constant voltage, varying the charging current throughout the charging process until the current drops to almost zero. In contrast, the CC charging mode is widely used for nickel-metal hydrate batteries and nickel-cadmium batteries, as well as lithium-ion batteries, where a constant current is supplied by varying the charging voltage. In the case of CC, at the start of the charging process, the battery system utilizes much higher power until the battery voltage reaches a pre-set voltage. If this high power is not managed well by the charge controller, the battery will overcharge. This may cause gassing and overheating issues, leading to system damage and a decrease in the battery life cycle, due to a higher rate of current injection under lower charging conditions. However, drawing excessive power can be avoided in the $\mathrm{CV}$ charging method. Hence, it is more efficient to use the CC-CV in the application of lithium-ion batteries as it improves the performance and life of the battery, limits the charging current and voltage-protecting from over-voltage and over-current-controls the injected power, and reduces thermal stress, as well as enabling rapid charging. The lithium-ion battery is charged in two main stages: in the CC mode, a constant current is applied by the battery controller until it achieves $70-80 \%$ of its SoC and the battery's cell voltage reaches a certain voltage level. This is followed by the $\mathrm{CV}$ charging mode, where the current level is reduced until it reaches zero, while maintaining a constant voltage level. This protects the battery from damage due to overcharging. 
Since the storage model in OpenDSS cannot handle the CV charging mode, only CC charging is considered in this study. MATLAB has been used to develop this CC functionality. This is sufficient to understand the charging/discharging behavior of the eCook batteries, the technical impact on the grid, and the advantages of using this control strategy.

Furthermore, the behaviors of batteries are highly dependent on the charging rate $(\mathrm{C}$ rate). The $\mathrm{C}$-rate can be defined as the measure of the rate at which a battery is discharged, relative to its maximum capacity - the shorter the charge/discharge time, the higher the current required [20]. When using a high C-rate, the charging speed is improved, although it accelerates degradation and causes more rapid deterioration of both the capacity and the power capability of the battery. More importantly, this could result in negative impacts on the distribution network (voltage fluctuation and new system load peaks). In the case of a lower C-rate in battery charging, high-capacity utilization is achieved with fewer negative effects on power network performance. However, if the C-rate is too low, this will slow down the battery-charging speed. Hence, the main challenge is to select a suitable C-rate that is capable of equilibrating the battery charging speed and capacity utilization, without violating network constraints. For lithium-ion batteries, it is recommended that they should charge at $0.8 \mathrm{C}$ or less to prolong battery life [21], but this will depend on the manufacturer and the application (for example, Mastervolt recommends a maximum of $0.3 \mathrm{C}$ [22]). This paper, therefore, analyses the effect of five different $C$-rate values on the performance of the mini-grid network.

From the authors' point of view, the main questions to be considered when connecting eCook batteries to the mini-grid network are:

- What are the technical network constraints that can occur when deploying eCook batteries?

- What is the most suitable eCook battery C-rate capable of maintaining the network constraints within the thresholds, during the charging window?

- What are the alternatives and solutions to enable uptake and maximize the number of eCook batteries connected to the network, without violating network constraints?

The remainder of the paper will focus on addressing these questions by conducting a technical assessment and developing contextualized case studies, to explore the concept of a "smart" eCook management system.

\section{Mini-Grid Network Modelling with eCook Batteries}

\subsection{Modelled Mini-Grid Network with eCook Batteries}

The hybrid mini-grid shown in Figure 1 was modeled and used in a previous publication related to this research study [9], which was developed as a composite of those systems designed and installed by practitioners and based on the mini-grid design methods available in the literature. The mini-grid network was modeled using the open distribution system simulator (OpenDSS) /MATLAB software (R2021a) [23].

To understand the charging/discharging behavior of eCook batteries, the technical impact on the grid and their advantages, the batteries were allocated to $47 \mathrm{HHs}(\approx 43 \%$ of total HHs) connected to the mini-grid network (starting with those connected HHs furthest from the power station). To explore most of the generated daily PV output power needs, a $10 \mathrm{~kW}$ PV-inverter (adequate to accommodate the network baseload) was replaced with one of $25 \mathrm{~kW}$, and the size of the centralized battery used in the previous study [9] was reduced from $41.4 \mathrm{kWh}$ to $27.6 \mathrm{kWh}$. Hence, the mini-grid network studied in this paper includes a $30 \mathrm{~kW}$ PV, $25 \mathrm{~kW}$ PV-inverter, $27.6 \mathrm{kWh}$ centralized battery, and $8 \mathrm{~kW}$ converter. In terms of the distribution and service cables, the CSA is set to $50 \mathrm{~mm}^{2}$ and $16 \mathrm{~mm}^{2}$, respectively. As can be seen in Figure 1, the shaded HHs have batteries available to support their cooking.

The daily non-eCook (i.e., baseload) and the eCook load profiles used throughout the simulations are the same as those in the previous paper [9]. These were generated using 
the CREST [24] demand model by a group of researchers in the Modern Energy Cooking Service (MECS) team [25].

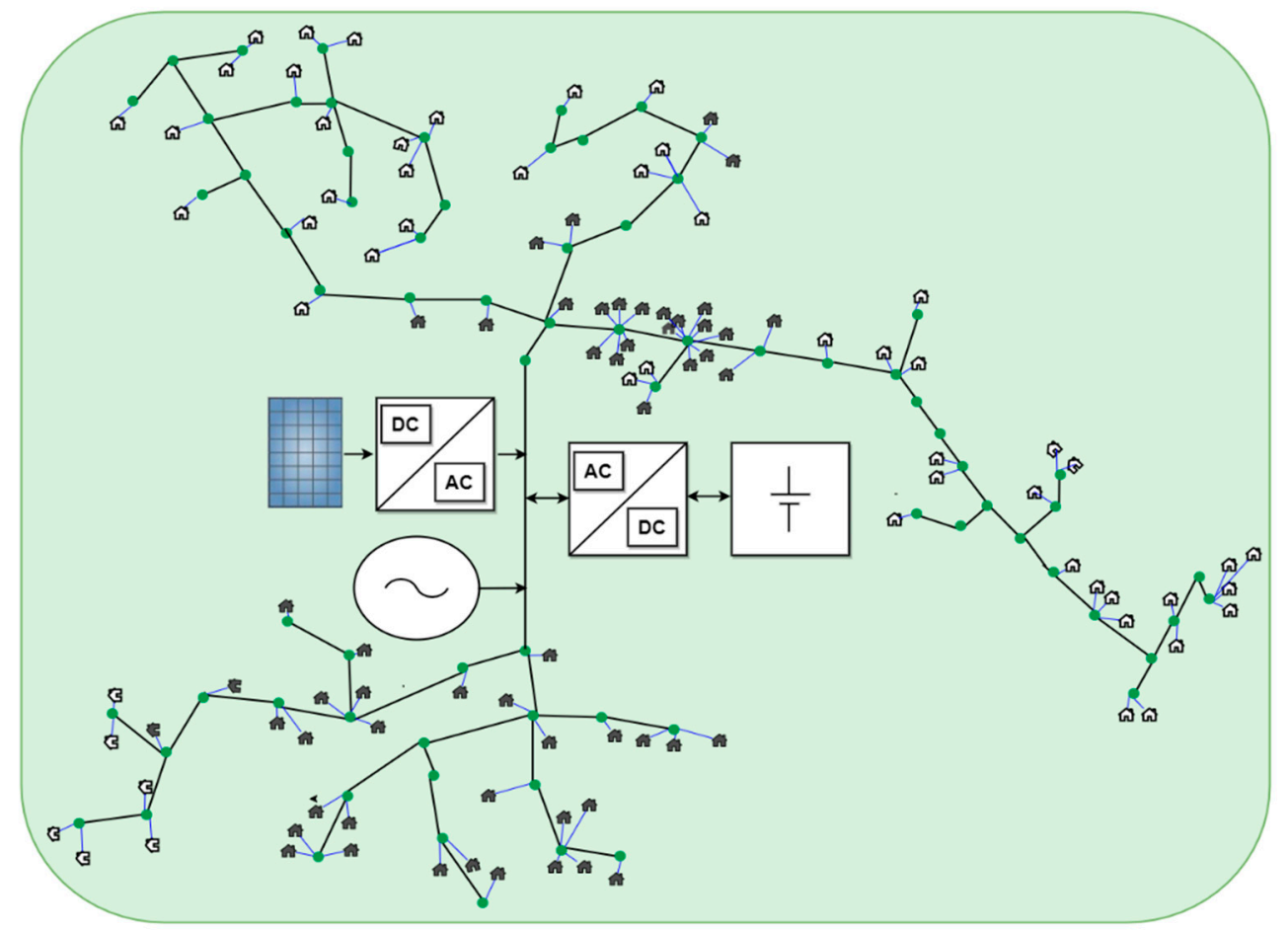

Figure 1. OpenDSS hybrid PV/diesel mini-grid layout (the gray shaded HHs have eCook batteries).

The report by M. Leach and R. Oduro [26] was used as a reference for the steps to be followed when calculating the eCook battery capacity. The average daily energy cooking consumption is $1.6 \mathrm{kWh}$ and is based on the characteristics of the lithium-ion battery in Table 2; the battery capacity is calculated at $6 \mathrm{kWh}$. Here, the batteries are sized to only meet the morning and evening cooking demand, while at midday, the PV power generation and the backup diesel generator are used to enable the HHs to cook food (thus limiting the eCook battery size). To improve the battery's performance during its mid-life design, additional factors are considered in the system sizing; these values are highly sensitive to the depth of discharge (DoD), C-rate, and temperature. These factors are the batteries' lifetime aging and life cycle; also, in the case of a hot climate, where the average temperature is around $33{ }^{\circ} \mathrm{C}$, the life cycle of a lithium-ion battery reduces to $20 \%$ of its rating under ambient temperature, due to internal chemical reactions. Hence, it is important to limit the DoD to $80 \%$ or less to prevent harm to the eCook batteries, prolong their life and minimize charging losses. For these reasons, in this paper, the minimum and maximum states of charge $(\mathrm{SoC})$ are set at $20 \%$ and $80 \%$, respectively [27]. The round-trip efficiency of the battery and the bidirectional converter efficiency were also considered in the calculations.

Table 2. Assumption of lithium-ion parameters.

\begin{tabular}{cc}
\hline Description & Lithium-ion \\
\hline Autonomy (days) & $\approx 1 / 2$ day \\
Battery voltage & $24 \mathrm{~V}$ \\
Round-trip efficiency & $\approx 90 \%$ \\
Additional battery capacity for & $10 \%$ \\
decay over time & 2000 cycles at $100 \%$ DoD (depth \\
Lifetime of the battery & of discharge) \\
\hline
\end{tabular}




\subsection{The Mini-Grid Network Central Controller and Distributed eCook Battery Charge Controller Algorithm}

As shown in Figure 2, the mini-grid's central controller instructs the generators to control and manage their behavior, while the battery's charge controller optimally regulates the voltage and current flowing to and from the batteries, preventing them from overcharging and under-discharging.

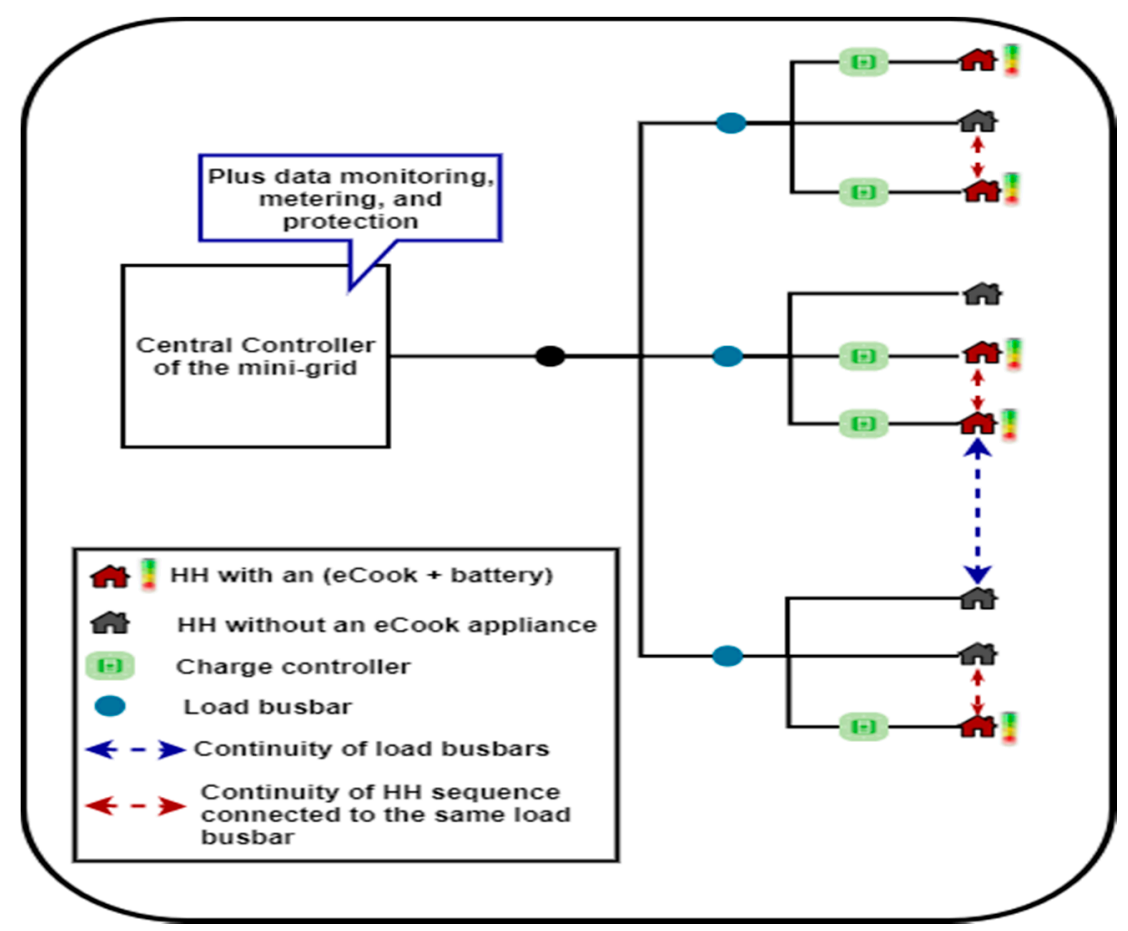

Figure 2. A simplified diagram showing the mini-grid components.

Figure 3 illustrates the principles of operation for the central controller and the eCook battery charge controller algorithms, which were developed in MATLAB. These can be summarized in the following steps:

1. Once the PV output power is equal to the aggregated load power (baseload plus midday cooking demand (P2)), the PV array has a higher priority to fulfill the entire demand (Figure 3). The second priority is given to the centralized mini-grid battery and the last priority is to the backup diesel generator.

2. The excess PV power is used to charge the centralized battery if it is not fully charged, then the new surplus network power is calculated, which will be used to charge the eCook batteries.

3. The eCook batteries are charged by a so-called uncontrolled charging method. The only control that is assumed to be available is the ability (at any given time) to charge the batteries safely, avoiding under- or overcharging using a conventional charge controller when there is a surplus generation of power from the PV. Limited power also implies that only a limited number of eCook batteries can charge simultaneously. The logical flow for charging the eCook batteries is, first, to find the number of batteries $(\mathrm{N})$ that could be charged, depending on the available surplus PV power. In the case where there is enough power to charge one or more batteries, the charging takes place, starting with those $\mathrm{HHs}$ with the lowest SoC levels. If there is no excess power, the eCook batteries are put into idling mode.

4. A minimum $\mathrm{SoC}$ is required before the power discharging takes place. The eCook batteries at each $\mathrm{HH}$ level start to discharge to meet the early morning (P1) and evening (P3) cooking demands. When the batteries are in discharging mode, they 
follow the HH demand curve. In this case, the discharging current is limited to the maximum current rating of the inverter.

5. If the SoC of the eCook battery is not sufficient to cook breakfast or dinner, the backup diesel generator is brought online to meet the cooking netload.

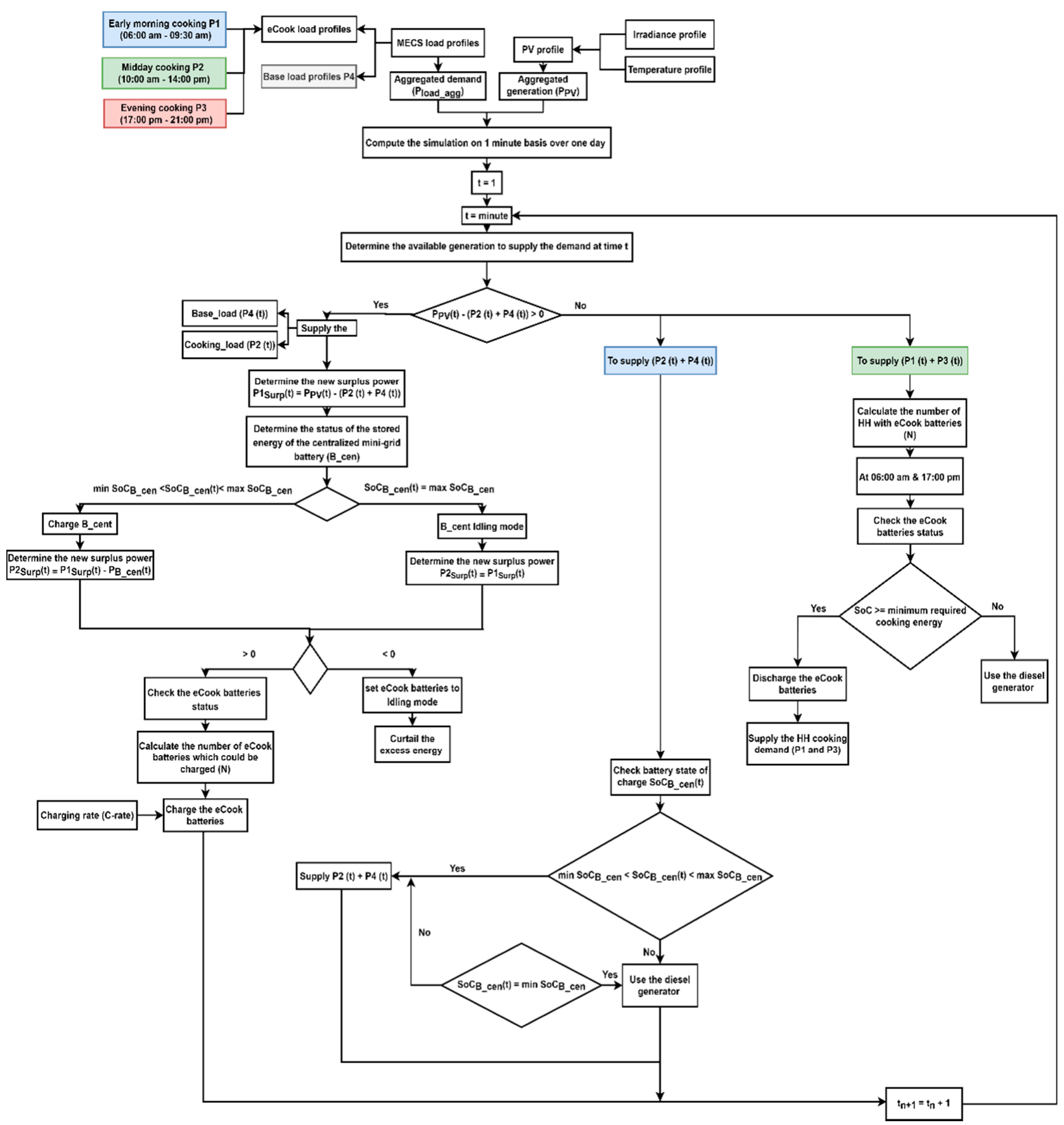

Figure 3. The mini-grid central controller and the eCook battery charge controller algorithm.

\section{Assessing the C-Rate Impact on Network Constraints}

This study assesses the impact of varying the C-rate on the network constraints (Figure 4) as key controllable parameters when charging the eCook batteries. The findings of this study are beneficial in moving forward toward developing a smart eCook battery charge management system, to prevent significant network reinforcements or upgrades. 


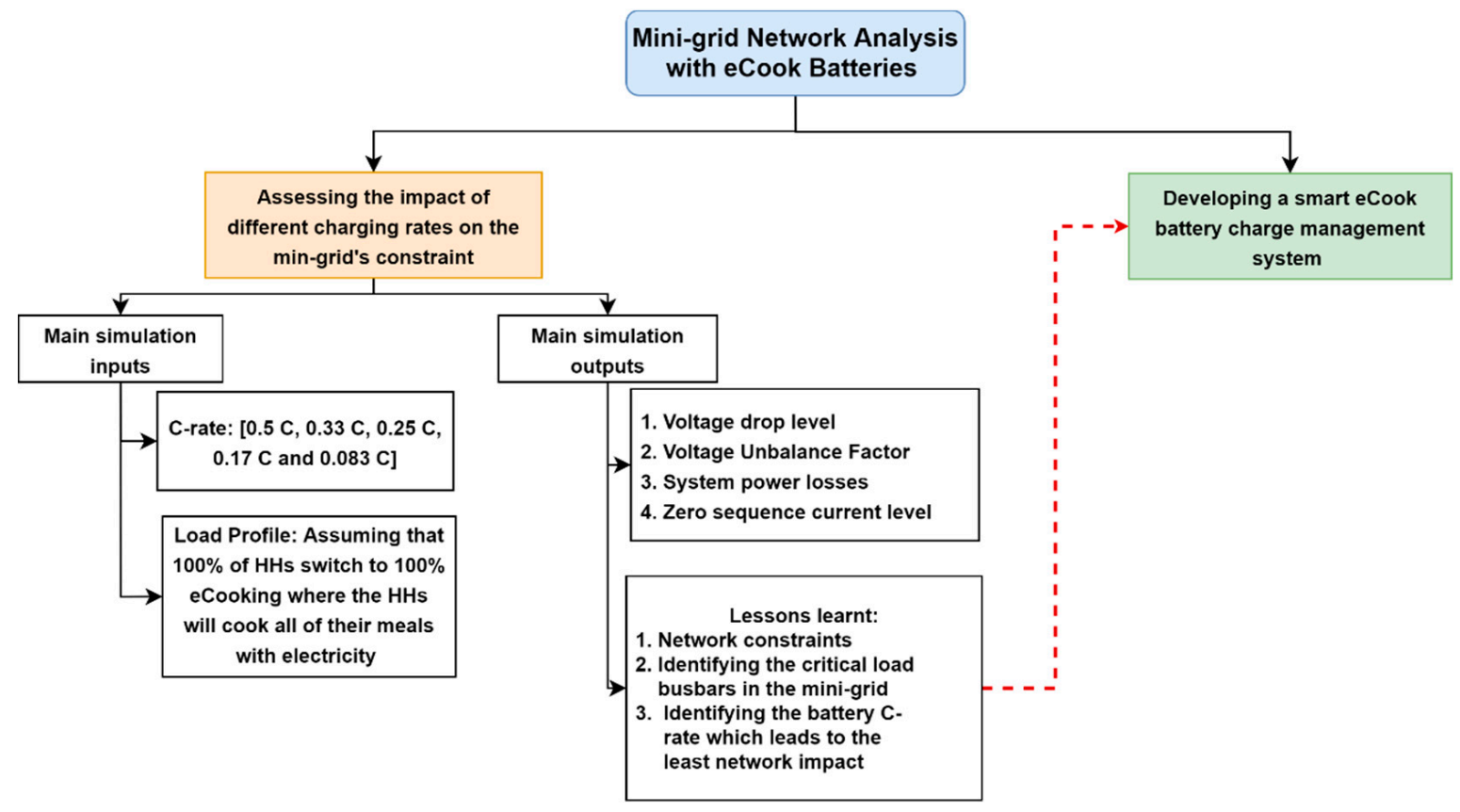

Figure 4. Assessing the C-rate impact on network constraints.

The study investigates the impact of different eCook battery C-rates on the performance of the distribution network. As mentioned in Section 3.2, at a high C-rate, the eCook batteries will successfully charge more rapidly; however, the network could experience high voltage fluctuations, system power losses and additional demand when the battery charges during sunlight hours.

The network model and the battery-charging algorithm were tested on five different case studies where, in each domestic situation, the eCook batteries are charged at different C-rates, these being $0.5 \mathrm{C}, 0.33 \mathrm{C}, 0.25 \mathrm{C}, 0.17 \mathrm{C}$ and $0.083 \mathrm{C}$, respectively, and where the input charging power is $3 \mathrm{~kW}, 2 \mathrm{~kW}, 1.5 \mathrm{~kW}, 1 \mathrm{~kW}$ and $0.5 \mathrm{~kW}$, respectively. The choice of battery C-rate values allows the performance of the mini-grid to be assessed in terms of both fast and slow charging, as well as providing a wider range of results and establishing a better understanding of the technical impacts. It should be noted that some eCook batteries could charge faster, as they are partially charged while waiting in the queue, since attention is focused on those with the lowest SoC. The network studies are carried out to evaluate the C-rate with the least network impact on the voltage drop constraint, VUF, system power losses and zero-sequence current level.

As highlighted in Figure 4, in this section, it is assumed that HHs with eCook batteries have transitioned to $100 \%$ eCook-meaning that all the $\mathrm{HH}$ food is cooked by eCook, where a hotplate is used for breakfast and lunch while, for dinner, either or both the hotplate and an EPC are used. This cooking pattern is considered to be the worst-case scenario (in terms of high demand level), which emphasizes the need to study and understand the upcoming trends and challenges.

Throughout this study, the maximum voltage drop and VUF are $5 \%$ and $2 \%$, respectively. These values follow international norms and are in line with reference documents [25,28-30] of mini-grid design, as well as national grid standards to mitigate any technical and investment risks when the main grid arrives.

\section{Simulation Results and Discussion}

Figure 5 illustrates the maximum VUF level throughout the simulation at each load busbar of the residential feeder; in the x-axis, the busbars are arranged in descending order with reference to their distance. The results show that the level of the C-rate has a significant impact on the performance of the grid. At a high C-rate (case 1, case 2 and case 3 ), the network 
experiences more stress at the load busbars that are far from the power source, particularly those busbars at the end of the feeder connected to HHs with eCook batteries. The VUF goes beyond the allowed limit of $2 \%$ for case 1 , due to the unequal distribution of these batteries along the distribution line, where each phase experiences different voltage drops.

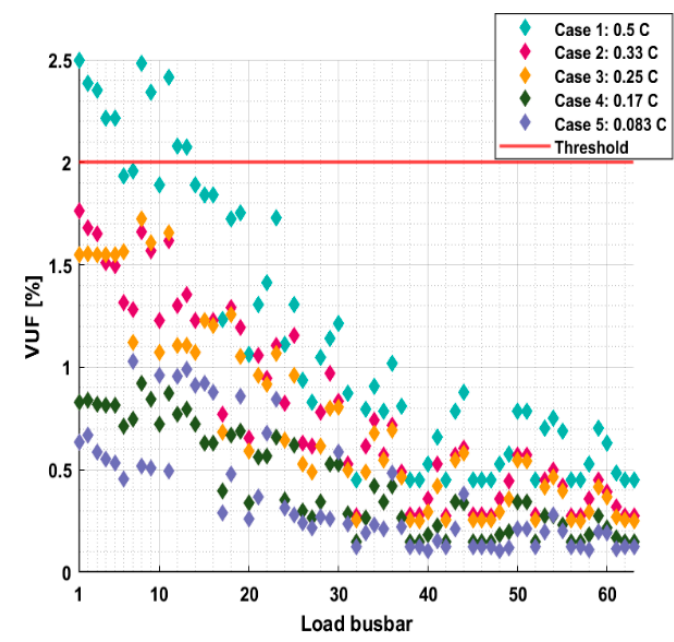

Figure 5. The maximum VUF value that occurs throughout the daily network simulation at each load busbar.

The eCook batteries are characterized by a high single-phase power rating, leading to an imbalanced system impedance, meaning that during the charging process, a phase imbalance occurs, whereas a high flow of current through the distribution lines causes an increase in system power losses (Figure 6), leading to a higher voltage drop at the end of the feeders. Consequently, the zero-sequence current (Iz) becomes higher in parts of the grid where the feeder length is significant (between approximately $0.8 \mathrm{~km}$ and $0.38 \mathrm{~km}$ ), which could result in damage to the grid's infrastructure when the operational and network constraints are exceeded.

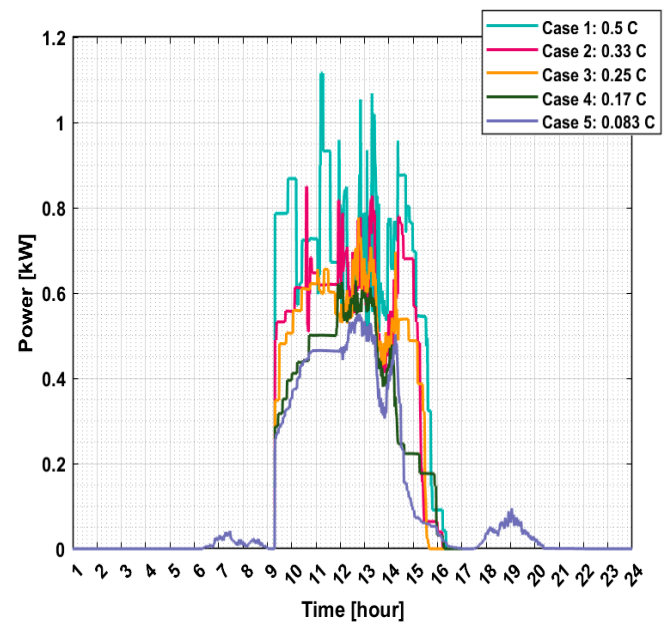

Figure 6. The total system power network losses.

At maximum VUF, the voltage drop for each case was recorded and plotted in (Figures 7-11). From the findings, it is clear that the voltage drop exceeds the allowed limit $(5 \%)$, in particular at those busbars connected to charging eCook batteries that are at a distance from the substation. It is noticeable that the case studies with high C-rates (case 1, case 2 and case 3 ) experience a high voltage drop at phase $C$, compared to phase A and $\mathrm{B}$, due to most of the charging eCook devices being connected to phase C. The VUF and 
voltage drop levels depend mainly on the number of batteries charging simultaneously, their distribution along the feeder, and the SoC level. Any changes to these arrangements could initiate more severe network constraint violations.

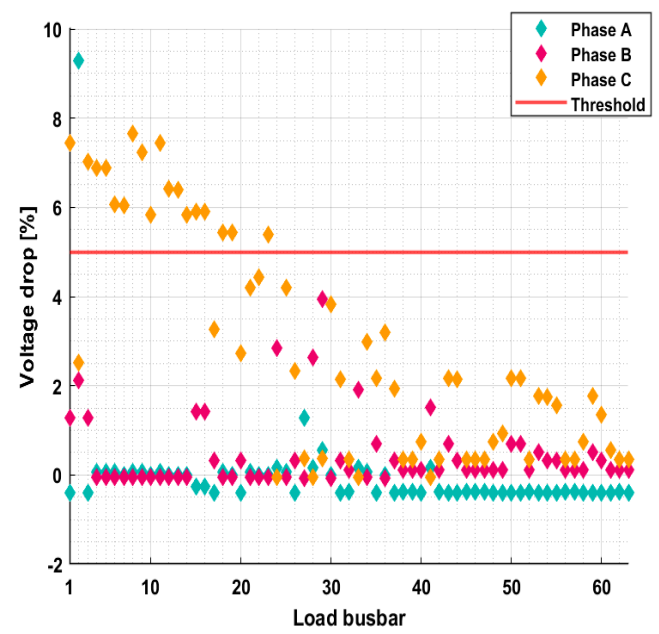

Figure 7. The load busbars' voltage drop (\%), obtained at maximum VUF for case 1 (0.5 C).

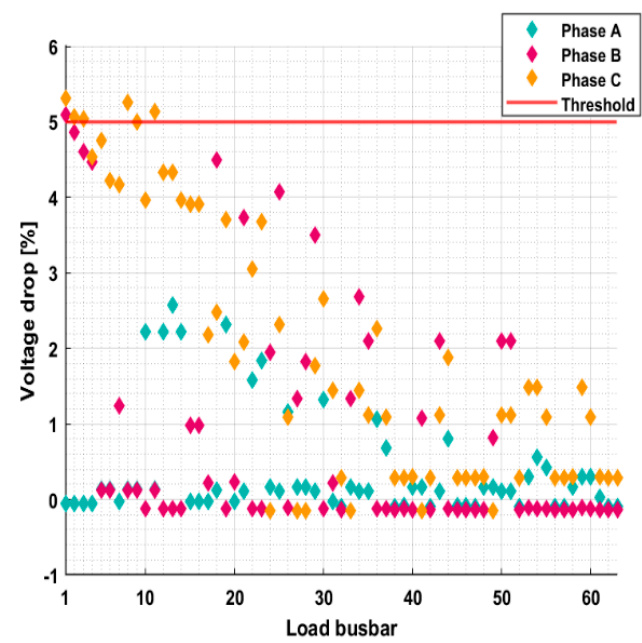

Figure 8. The load busbars' voltage drop (\%), obtained at maximum VUF for case 2 (0.33 C).

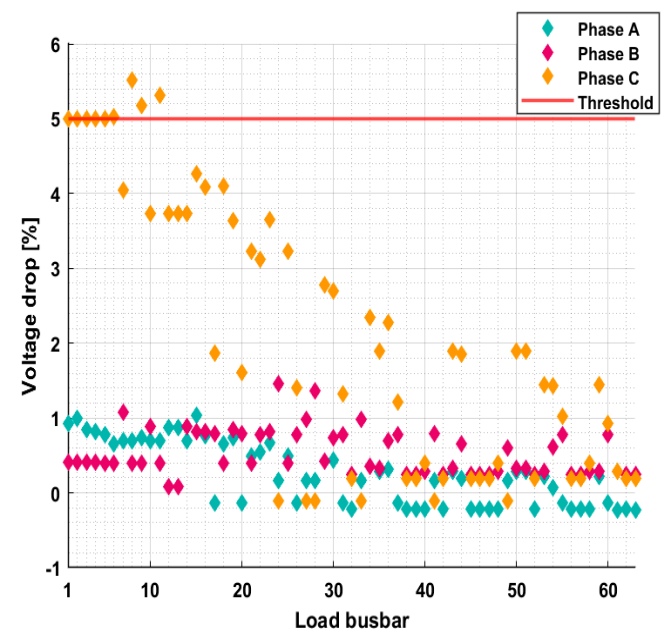

Figure 9. The load busbars' voltage drop (\%), obtained at maximum VUF for case 3 (0.25 C). 


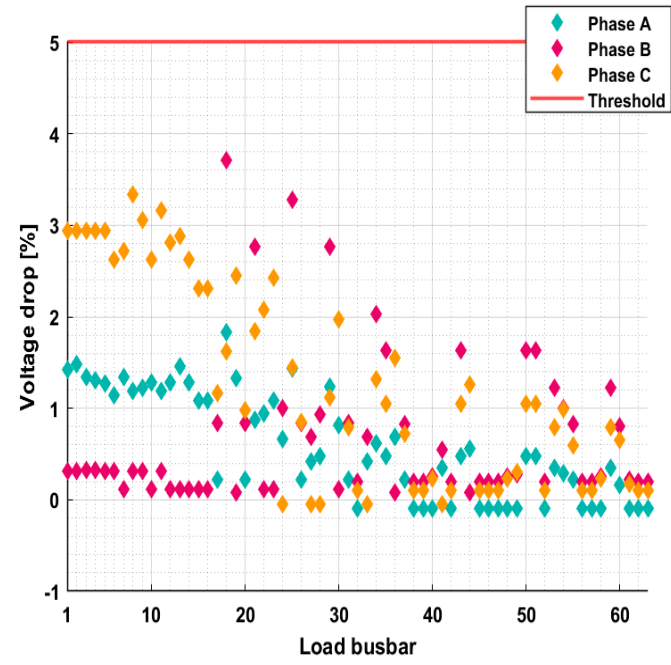

Figure 10. The load busbars' voltage drop (\%), obtained at maximum VUF for case $4(0.17 \mathrm{C})$.

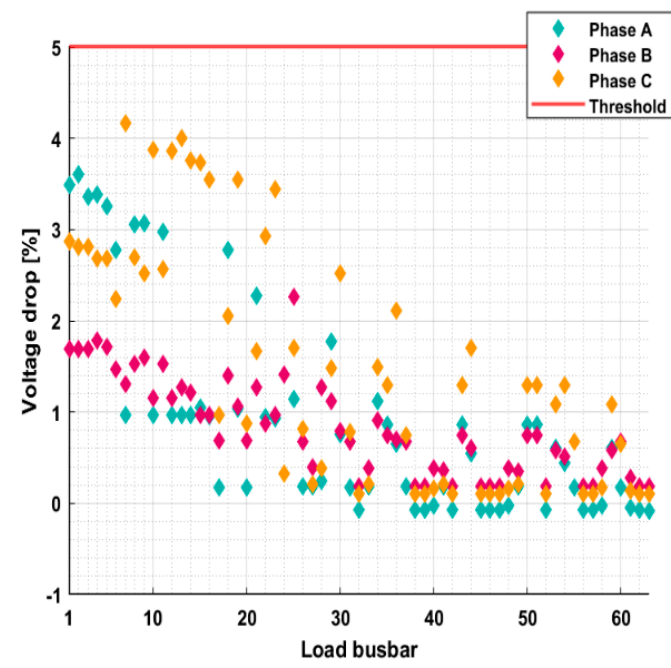

Figure 11. The load busbars' voltage drop (\%), obtained at maximum VUF for case 5 (0.083 C).

For a C-rate of $0.17 \mathrm{C}$ and $0.083 \mathrm{C}$, the voltage drop level remains below 5\% (Figures 10 and 11) and the network starts to operate within its constraints, with less current required to charge the eCook batteries, resulting in lower system power losses when compared with high C-rate charging. Therefore, fewer VUF and voltage drops are experienced, and the network operates within the allowed limits (2\% and 5\%, respectively).

The simulation results show that over a typical day, the network experiences excessive voltage drops at phases A, B and C in case 1, case 2 and case 3 (Table 3). However, it also shows that this can be avoided by using a low C-rate, as indicated in case 4 and case 5 . Naturally, the trade-off here is a longer charging period, as illustrated in Figure 12, which demonstrates the charging time for 30 eCook batteries, connected to the mini-grid, out of a total of 47 . From the results, the average charging time in case $5(4.65 \mathrm{~h})$ increases by approximately six times the average charging time of case $1(0.79 \mathrm{~h})$; therefore, it is evident that a high C-rate reduces the charging time, but it does not present a better solution from the perspective of the network's constraints. 
Table 3. Maximum voltage drops for different case studies.

\begin{tabular}{cccc}
\hline \multirow{2}{*}{ Cases } & \multicolumn{3}{c}{ Maximum Voltage Drop (\%) } \\
\cline { 2 - 4 } & Phase A & Phase B & Phase C \\
\hline $\mathbf{1}$ & 9.289 & 6.940 & 7.567 \\
\hline $\mathbf{2}$ & 6.760 & 5.555 & 5.315 \\
\hline $\mathbf{3}$ & 5.605 & 5.296 & 5.522 \\
\hline $\mathbf{4}$ & 4.567 & 4.961 & 3.683 \\
\hline $\mathbf{5}$ & 3.853 & 3.320 & 4.160 \\
\hline
\end{tabular}

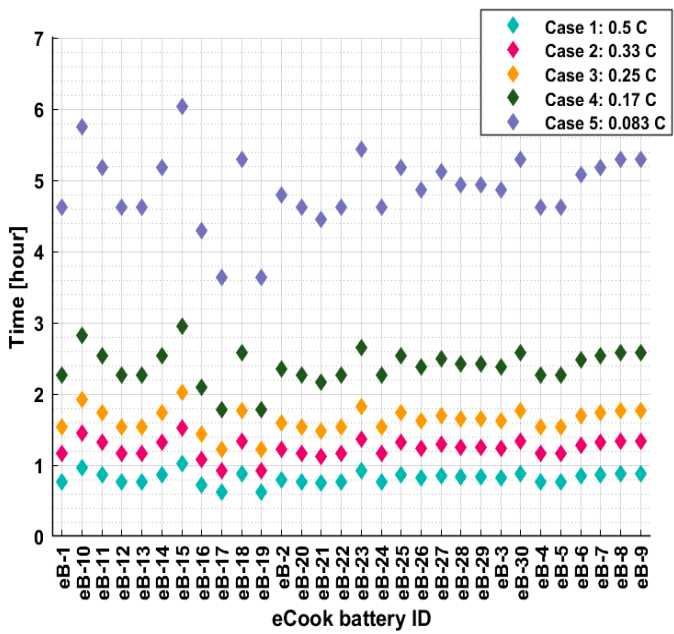

Figure 12. The charging time for each eCook battery, with respect to each charging rate.

To conclude this section, the main observations obtained from the results are:

- The eCook batteries are considered to be flexible loads with respect to the charging power, by changing the C-rate value.

- Using a high C-rate causes a high voltage drop and VUF; therefore, there is the opportunity to utilize lower C-rates for charging eCook batteries, to maintain the network constraints within the limits, and to charge a wider distribution of $\mathrm{HH}$ eCook devices.

- The location of the eCook battery along the feeder, and their concentration in a particular location, are two main factors to take into consideration when deploying eCook batteries since they can lead to a higher likelihood of network problems arising and can cause more pronounced phase losses.

- The number of eCook batteries charged during the day depends mainly on:

$>\quad$ The daily surplus PV energy, since this decides the number of eCook batteries that can be charged simultaneously.

$>\quad$ The SoC, which decides the duration of the charging period for eCook devices.

$>\quad$ The choice of C-rate value: from observations, it was noticed that fast-charging batteries on a cloudy day, when solar resources are limited, results in the cumulative charging of fewer batteries than when using a lower C-rate for slow charging. This is because the required charging power is relatively high; when a group of batteries are in charging mode, they are forced by the conventional charge controller to continue recharging until they reach full SoC (on the condition that there is enough surplus PV power) before allowing the other $\mathrm{HH}$ batteries to commence charging. This inhibits the capacity of the other batteries waiting to recharge to do so. On the other hand, slow charging enables additional batteries to charge simultaneously, as the surplus PV power can be distributed between more batteries since the input charging power is lower. In 
the simulation, these batteries ultimately reached an average SoC of around $54 \%$, which is sufficient to meet the evening cooking demand.

The simulation results demonstrate how the smart charging of flexible eCook battery loads can be used to mitigate some of the preconceived network risks associated with inflexible, directly connected electric cooking loads.

\section{A Smart eCook Battery Charge Management System to Maximize eCook Demand within Network Constraints}

The previous section presented simulation studies conducted to appraise the feasibility of utilizing the charging rate of eCook batteries as a mean to manage the network constraints when eCook demand increases on a mini-grid. However, this section considers how this model can be implemented in a smart eCook battery management system (EBMS), to maintain the system within its constraints, and to adapt to both cloudy and sunny days with the objective of maintaining an acceptable standard and quality of eCook charging service.

The EBMS is divided into two parts, as shown in Figure 13. The first part of the system should be installed at the generator site and is referred to here as the central eCook battery management system (C_EBMS). The second part is installed at the load busbar where at least one eCook battery is connected, which is referred to as the distributed eCook battery management system (D_EBMS).

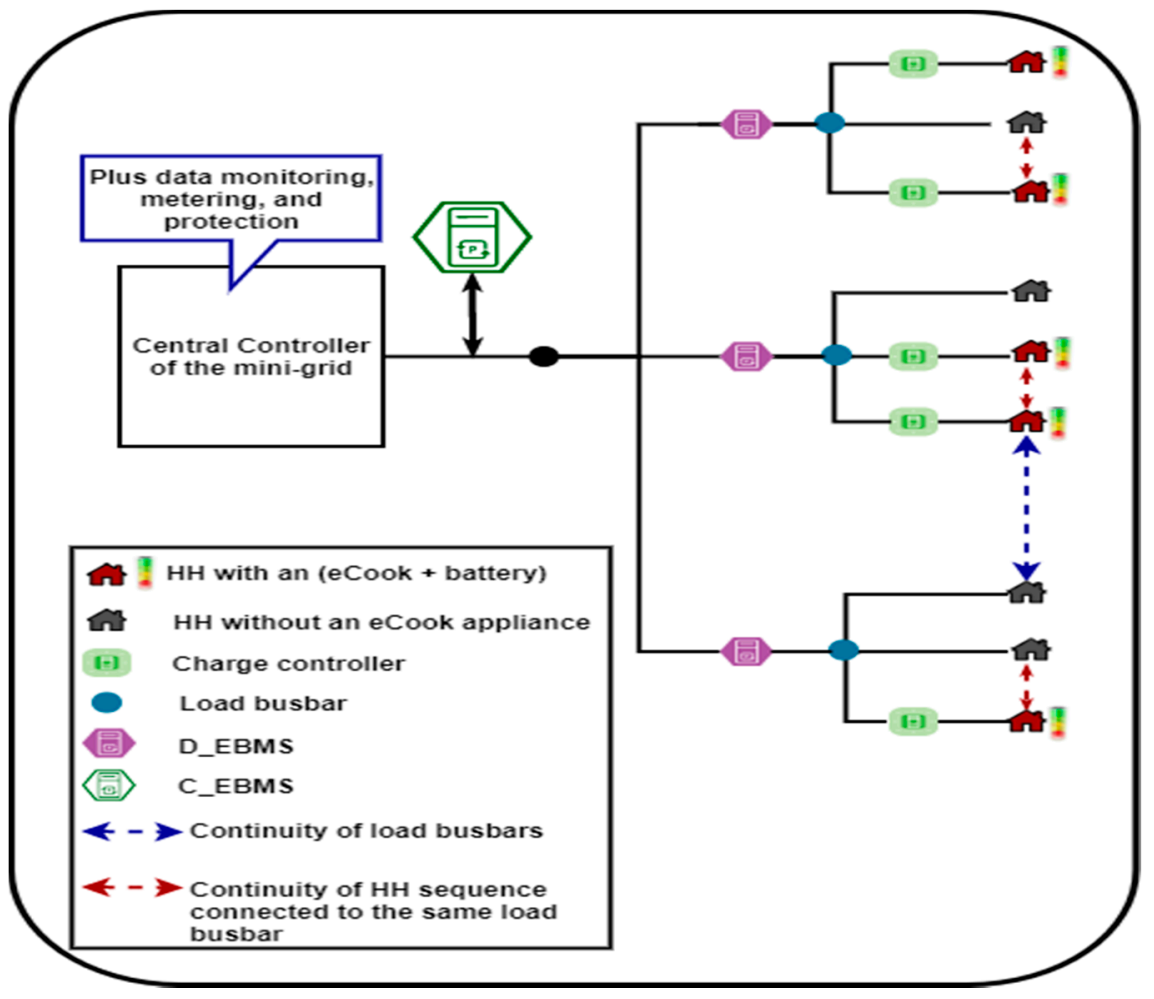

Figure 13. A simplified diagram showing the mini-grid components, including the two EBMS types (D_EBMS and C_EBMS).

The schematic diagram in Figure 14 represents the command flow for the eCook smart controlled charge service. As shown in Figure 14, once the eCook battery is in charging mode, the D_EBMS constantly checks the battery's SoC-if it is less than the required/desired SoC level required to cook a meal (e.g., $54 \%$ in the case study above) the battery recharges with the appropriate C-rate level (e.g., C-rate ${ }_{(\text {low })}$ of $0.083 \mathrm{C}$ ). When the $\mathrm{SoC}$ reaches the required level, the $\mathrm{C}$-rate is switched to a higher $\mathrm{C}$-rate to speed up charging 
when possible (e.g., C-rate ${ }_{(\text {high }}$ of $0.25 \mathrm{C}$ ). The C-rate is therefore gradually increased as more eCook devices charge, while working in line with the network constraints.

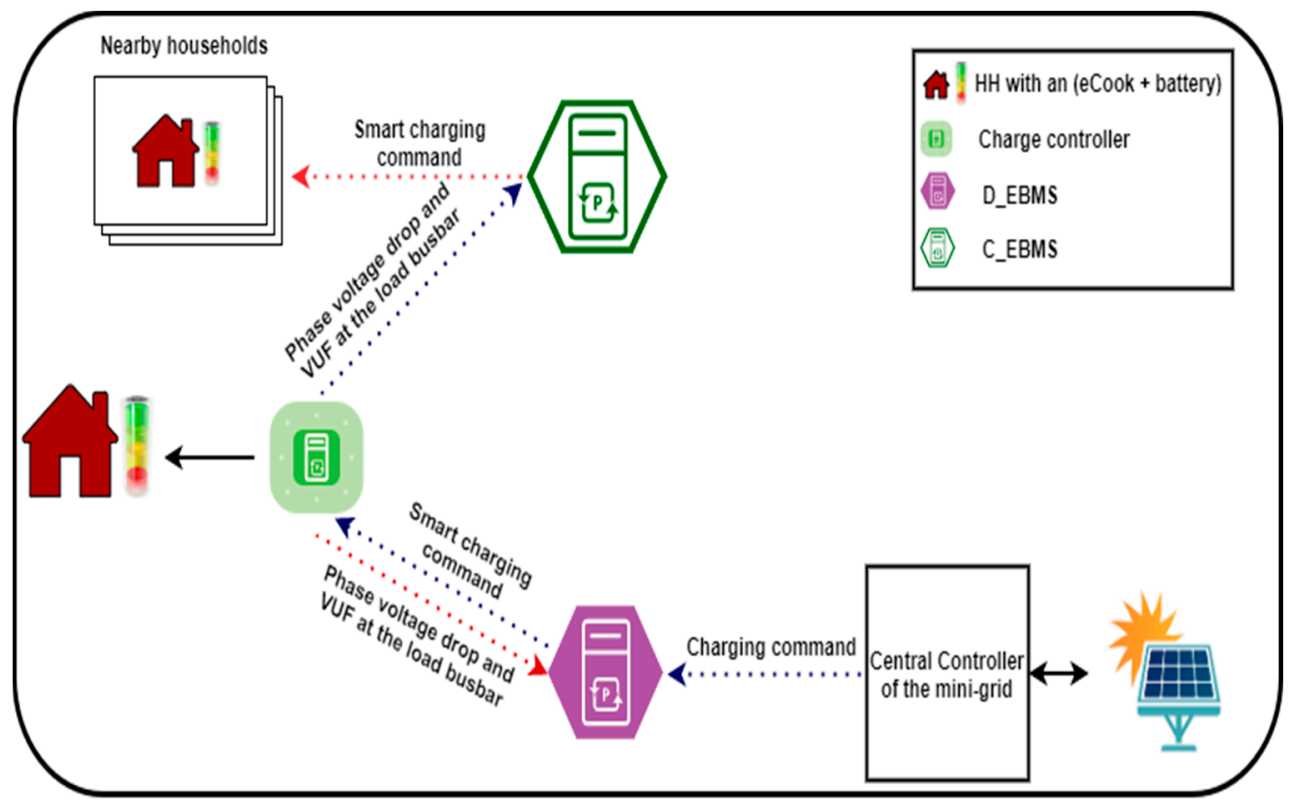

Figure 14. Command flow for the eCook controlled charge service.

At this point, the D_EBMS starts monitoring the state of the mini-grid by constantly measuring the VUF and voltage drops along each of the feeder circuit phases. If these values exceed their normal operational range ( $2 \%$ and $5 \%$, respectively), the eCook battery is forced to switch back to C-rate (low) $_{\text {. }}$.

If the network constraints are still violated, perhaps due to the eCook batteries that are connected nearby indirectly contributing to the voltage drop and phase imbalance, as they may be charging at C-rate (high) and drawing high charging power, then the C_EBMS assumes control, sending commands to the selected batteries, forcing them to charge at C-rate $($ low)

\section{Simulation Results and Discussion}

The sets of simulation results are shown in (Figures 15-18) to evaluate the feasibility of the proposed EBMS. The figures show the 24-h VUF and the three-phase voltages (A, $B$ and $C$ ) obtained at different load busbars of the feeder (these being the furthest load busbars of the distribution network). The results reveal that the proposed EBMS maintains the output voltage and VUF within the set limits. In Figures 16 and 17, when the voltage dropped below the allowed limit at 10:58 am and 11:17 am (circled in black), respectively, the EBMS detected the problem and adjusted the C-rate of the eCook batteries to $0.083 \mathrm{C}$, allowing the voltage to recover while maintaining the charging regime. The same response is observed at 11:22 am, 11:31 am and 12:39 am, as illustrated in Figure 18.

Here, the voltage drop levels could exceed $7 \%$, depending on the number of batteries charging simultaneously, their location along the feeder, their relative SoC, and their position in the queue. However, as can be seen from the analysis, the EBMS successfully operated within the network constraints. 


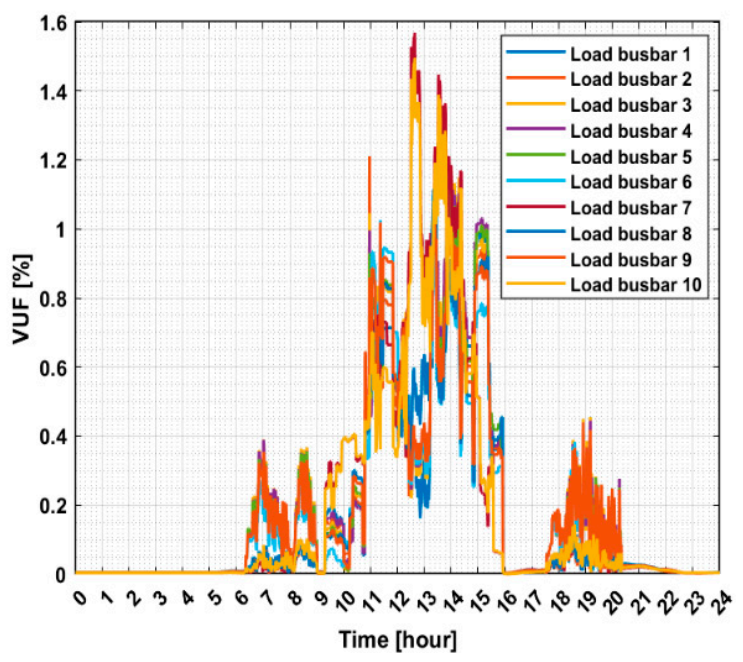

Figure 15. VUF daily profile at load busbars from 1 to 10.

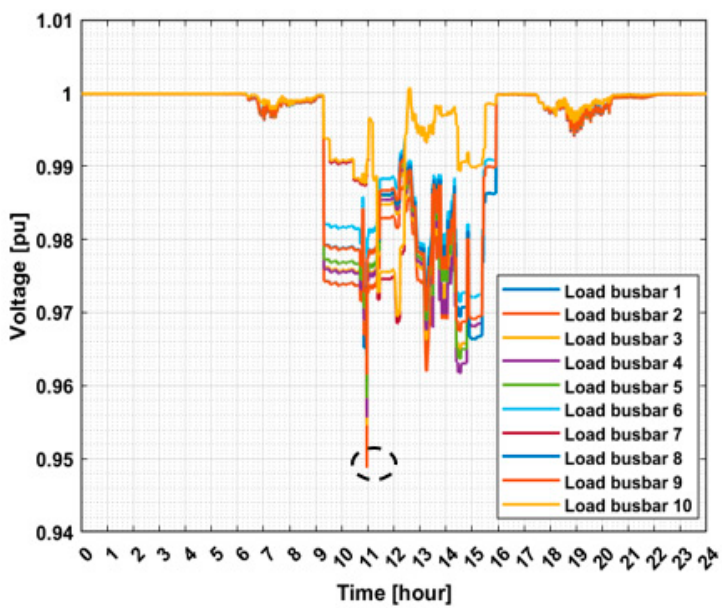

Figure 16. The voltage daily profile of phase A at load busbars from 1 to 10 .

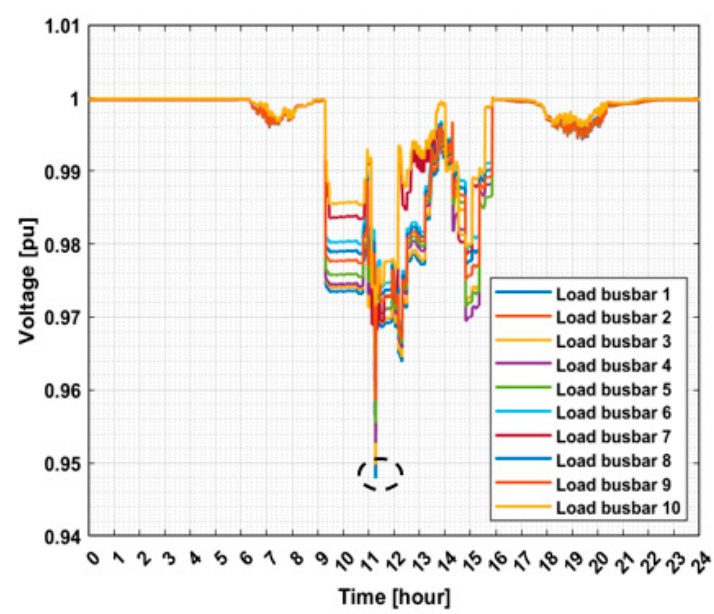

Figure 17. The voltage daily profile of phase B at load busbars from 1 to 10 . 


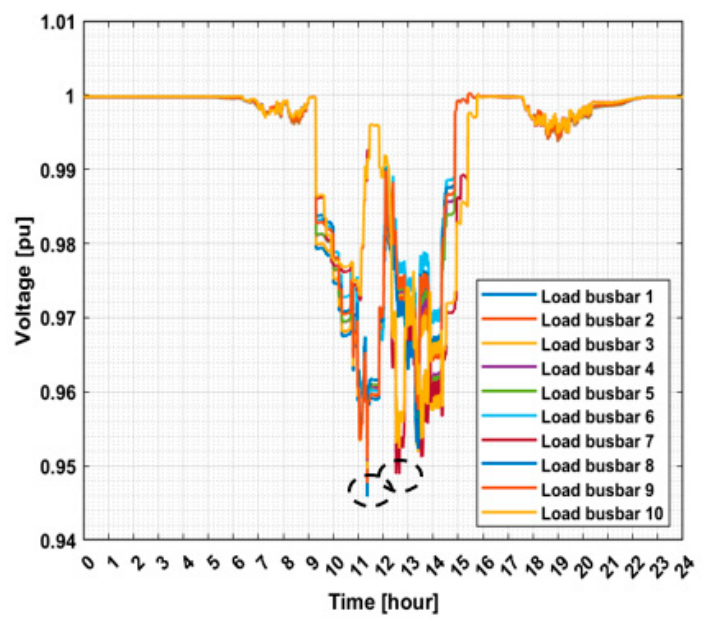

Figure 18. The voltage daily profile of phase $C$ at load busbars from 1 to 10 .

Connecting the eCook batteries significantly altered the network's operation. This section of the paper presented this EBMS control strategy as a viable option, in accommodating higher and more distributed eCook demand along with these feeders, while ensuring that the VUF remains within the standard allowed limits. Another advantage of this approach is that a combination of slow and fast charging is permitted, resulting in successfully reducing the charging time, compared to case 5 (see Figure 19), which shows the charging time of 30 eCook batteries out of a total of 47), where the average charging time was reduced by approximately $62 \%$. Using the EBMS also permitted an increase in the number of eCook batteries to be recharged on a cloudy day to meet the evening cooking needs, with a fraction of the batteries having enough charge to cook breakfast the following day, while on a sunny day, all 47 eCook batteries are charged enough to cook both meals (dinner and breakfast). On both sunny and cloudy days, lunch demand is directly supplied from the PV/diesel, as well as from the centralized battery.

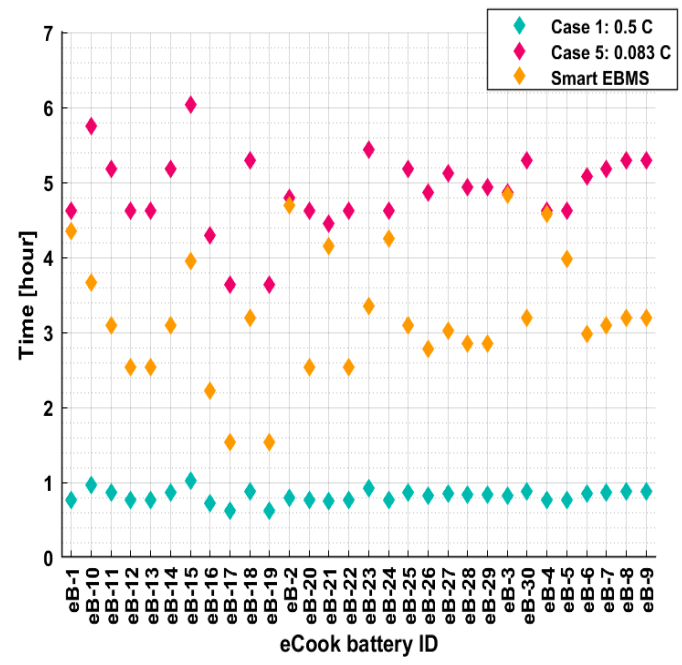

Figure 19. The charging time for each eCook battery, with respect to each charging rate.

\section{The Quality of Service of eCook Battery Charging}

In this study, the QoS of eCook battery charging is defined, based on the number of batteries recharged on a daily basis to meet evening cooking demand. The QoS analysis was conducted for four case studies, each considered on both a sunny and a cloudy day.

- "Direct Electric Cooking" case study: an electric cooking device with no battery storage, connected directly to the mini-grid. 
- "End of Feeder eCook" case study: a mini-grid network with eCook batteries connected at the end of the feeder.

- "Random Distribution \#1 eCook" case study: a mini-grid network, with eCook batteries randomly allocated to HHs (set 1).

- "Random Distribution \#2 eCook" case study: this is the same as the "Random Distribution \#1 eCook" case study but it takes another set of random values (set 2).

For "Direct Electric Cooking", on a sunny day, the system can accommodate approximately $20 \%$ eCook devices (representing $22 \mathrm{HHs}$ with eCook); however, on a cloudy day, this decreases to $6 \%$ ( 7 HHs with eCook) due to the lower PV output. Connecting eCook batteries offers more flexibility and maximizes the utilization of electricity, compared to "Direct Electric Cooking". In fact, from the results, on a sunny day, all 47 eCook batteries were recharged in each of the "End Feeder eCook", "Random Distribution \#1 and \#2" case studies, and were able to accommodate dinner and also breakfast demand the following morning. This capacity is reduced on a cloudy day, as illustrated in (Figures 20-22); these figures show the number of eCook batteries for each case study that have recharged with enough energy during the day to serve the evening's needs, as well as the number of batteries that have not charged, although they have enough energy stored as the battery size accounts for half-day autonomy. In terms of the conventional charge controller and EBSM, the total number of batteries available to serve the evening cooking demand in each case study is fewer than 47 eCook batteries. It is apparent from (Figures 20-22) that charging the eCook batteries with the smart-controller EBMS offers a higher QoS, as more eCook batteries are adequately recharged, ranging between 26 and 29 eCook batteries (55-62\%) (compared to a system without EBMS charging). These are discharged during the evening, and a limited number of batteries will still have enough stored energy to supply early morning cooking demand (around 12-15 eCook batteries, translating to 26-32\%).

Up until this point, the EBMS performance was studied when connecting only $47 \mathrm{eCook}$ batteries to the mini-grid (where $43 \%$ of HHs had an eCook battery), yet it is important to evaluate the maximum eCook battery penetration that could be connected to the type and size of the mini-grid studied in this paper. Figures 23 and 24 present the QoS of eCook battery-charging as a percentage, showing the eCook battery penetration for sunny and cloudy days, respectively. The eCook penetration is gradually increased from $40 \%$ to $100 \%$ (where 100\% refers to all $108 \mathrm{HHs}$ using an eCook battery) in each of these cases.

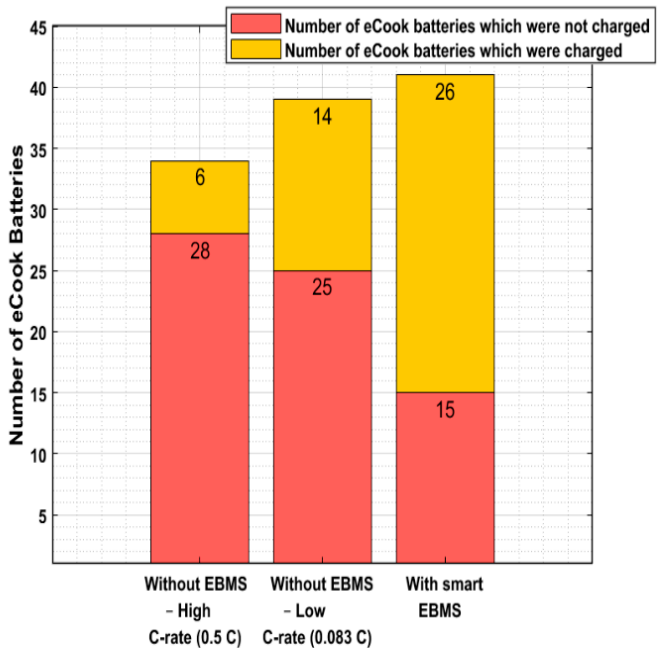

Figure 20. The number of eCook batteries available to meet dinner-cooking demand on a cloudy day for the "End of Feeder eCook" case study. 


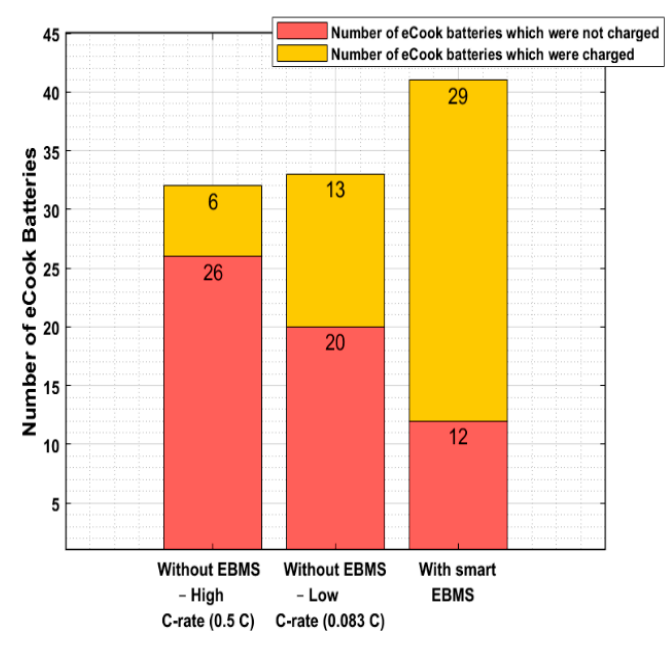

Figure 21. The number of eCook batteries available to meet dinner-cooking demand on a cloudy day for the "Random Distribution \#1 eCook" case study.

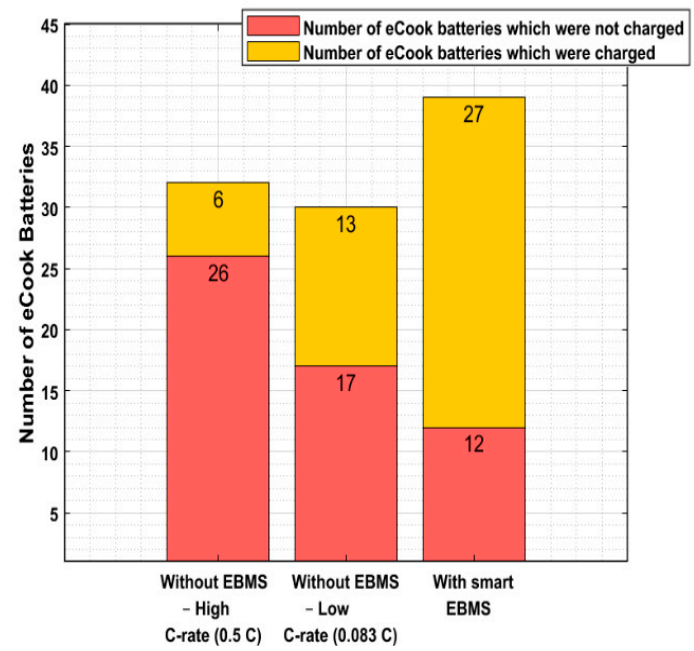

Figure 22. The number of eCook batteries available to meet dinner-cooking demand on a cloudy day for the "Random Distribution \#2 eCook" case study.

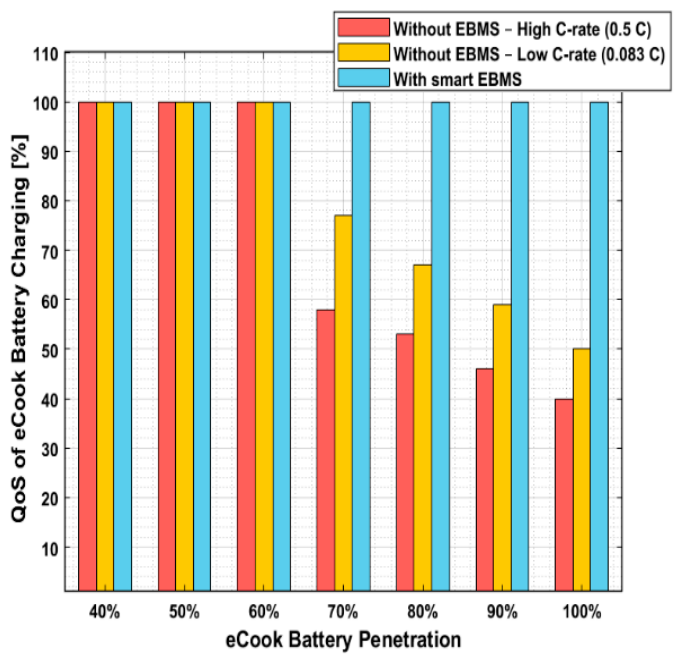

Figure 23. QoS of eCook battery charging for different eCook battery penetrations on a sunny day, with the power usage in the evening. 


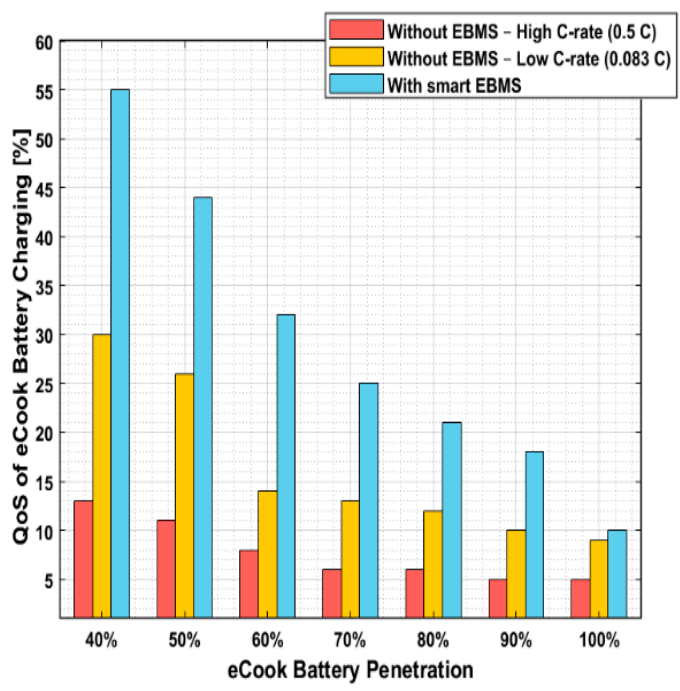

Figure 24. QoS of eCook battery charging for different eCook battery penetrations on a cloudy day, with power used in the evening.

It was found that, eventually, on a sunny day, the PV generated enough power to adequately recharge up to $60 \%$ eCook batteries in the case of conventional charging without the EBMS (see Figure 23). As illustrated in Figure 23, when the eCook battery penetration increases beyond $60 \%$, the QoS abruptly starts to reduce as they are not receiving any or enough charging service, due to the limited PV generation capacity required to charge the additional eCook batteries. In addition, when a group of batteries are in charging mode, they are forced by the conventional charge controller to continue recharging until the battery reaches full $\mathrm{SoC}$, before allowing the other $\mathrm{HH}$ batteries to commence charging. As can be seen, when using the smart EBMS, the charge distribution of the batteries is spread more equally, providing an improved overall QoS. As the eCook battery penetration increases, it enables all $108 \mathrm{HHs}$ to cook with electricity during the evening, and still enables $72 \%$ to $100 \%$ of the eCook batteries to provide enough power to cook breakfast the following day. Naturally, when there is a limited solar resource (Figure 24), this will have a direct impact on the number of eCook batteries that can be adequately charged. Where the eCook demand cannot be adequately met, then fuel stacking can be used as a form of "backup" [31]. A longitudinal study is needed that captures how this scenario plays out over the course of a year, in terms of eCook availability. As the eCook battery penetration increases, batteries will not normally be charged to their full capacity. Therefore, to ensure maximum utilization of the eCook batteries with the smart EBMS, it is considered practical that the system will enable $40 \%$ to $60 \%$ of $\mathrm{HHs}$ to cook $100 \%$ of their evening food with electricity, as well as most of the breakfasts, on a sunny day.

An alternative way to interpret these results is with the possibility of increasing eCook battery penetration beyond $60 \%$ when using the smart EBMS, by reducing the size of the eCook batteries; in this scenario, $100 \%$ of the HHs' evening meals will be cooked with electricity, while the remainder of the meals will be cooked with another type of cooking fuel. This option will encourage a gradual move toward cooking with electricity, as well as introducing health, resource, and cost-saving benefits.

\section{Conclusions and Future Work}

The network studies in this paper aim to give a clearer idea of the technical challenges when connecting eCook supported batteries to the hybrid PV/diesel mini-grid network. Charging the eCook batteries with a high C-rate causes increases in voltage drop and VUF that exceed the allowed limit of $5 \%$ and $2 \%$, respectively. This is mainly observed in the case of the load busbars furthest from the power source. Therefore, an innovative smart EBMS has been developed to allow C-rate adjustments to engage in voltage regulation, which operates by constantly verifying the voltage drop at each phase, as well as the VUF level. 
In general, the results show that the proposed EBMS can ensure that the network operates within voltage constraints. Moreover, the EBMS offers other significant advantages. First, it enables a combination of slow and fast charging that allows a greater battery charge coverage across the network, ensuring that eCook devices are ready for use in the evenings. Secondly, it provides the best QoS compared to a network without EBMS; thirdly, this approach could be used in the future, in concert with other flexible and non-flexible highpower appliances, to facilitate their uptake. However, further studies are required to evaluate the suitability and generality of the EBMS strategy presented here on different mini-grid models of different scales and topologies. Further work will also consider the optimization of the C-rate, to maximize eCook penetration over different mini-grid types and topologies.

It is clear that even when using this EBMS, there is still a need for a large eCook battery size $(6 \mathrm{kWh})$ to cook the daily meal with $100 \%$ electricity, which is not cost-effective. Therefore, instead of moving directly toward 100\% eCooking, fuel stacking can be seen as a viable solution to facilitate the transition (with EBMS smart-charging working alongside fuel stacking). This emphasizes the need to study and understand the upcoming trends of fuel stacking through developing a methodology to identify the lowest-cost, best-fit cooking scenario (with the optimal cooking solution incorporating eCook to a varying degree). This will be the subject of future research.

\begin{abstract}
Author Contributions: Conceptualization, S.K. and S.S.; methodology, S.K. and S.S.; software, S.K.; formal analysis, S.K.; investigation, S.K.; writing-original draft preparation, S.K.; writing-review and editing, S.K., S.S. and S.G. All authors have read and agreed to the published version of the manuscript.
\end{abstract}

Funding: This work was supported through the Engineering and Physical Sciences Research Council (EPSRC) Centre for Doctoral Training in Future Power Networks and Smart Grids (EP/L015471/1).

Institutional Review Board Statement: Not applicable.

Informed Consent Statement: Not applicable.

Conflicts of Interest: The authors declare no conflict of interest.

\title{
References
}

1. Zhang, Y. Accelerating access to clean cooking will require a heart-head-and-hands approach. Development 2021, 1-4. Available online: https: / link.springer.com/article/10.1057\%2Fs41301-021-00297-x (accessed on 15 December 2021). [CrossRef] [PubMed]

2. Ritchie, H.; Roser, M. Access to Energy. Available online: https:/ / ourworldindata.org/ energy-access (accessed on 14 October 2020).

3. World Health Organazation. Household Air Pollution and Health. Available online: https://www.who.int/news-room/factsheets / detail/household-air-pollution-and-health (accessed on 21 February 2020).

4. $\quad$ Bailis, R.; Drigo, R.; Ghilardi, A.; Masera, O. The carbon footprint of traditional woodfuels. Nat. Clim. Chang. 2015, 5, 266-272. [CrossRef]

5. Clean Cooking Aliance. 2021 Clean Cooking Industry Snapshot. Available online: https://www.readkong.com/page/2021 -clean-cooking-industry-snapshot-second-edition-4177518 (accessed on 20 September 2021).

6. Batchelor, S.; Brown, E.; Scott, N.; Leary, J. Two birds, one stone-reframing cooking energy policies in Africa and Asia. Energies 2019, 12, 1591. [CrossRef]

7. International Energy Agency; International Renewable Energy Agency; United Nations Statistics Division; The World Bank; World Health Organization. The Energy Progress Report Tracking SDG7: The Energy Progress Report (2019); International Renewable Energy Agency: Abu Dhabi, United Arab Emirates, 2019.

8. Clements, W.; Silwal, K.; Pandit, S.; Leary, J.; Gautam, B.; Williamson, S.; Tran, A.; Harper, P. Unlocking electric cooking on Nepali micro-hydropower mini-grids. Energy Sustain. Dev. 2020, 57, 119-131. [CrossRef]

9. Keddar, S.; Strachan, S.; Soltowski, B.; Galloway, S. An overview of the technical challenges facing the deployment of electric cooking on hybrid PV/diesel mini-grid in rural Tanzania-A case study simulation. Energies 2021, 14, 3761. [CrossRef]

10. Augusto, C.; Almeida, R.H.; Mandelli, S.; Brito, M.C. Evaluation of potential of demand side management strategies in isolated microgrid. In Proceedings of the 2017 6th International Conference on Clean Electrical Power (ICCEP), Santa Margherita Ligure, Italy, 27-29 June 2017; pp. 359-361.

11. SmartGrid.gov. Recovery Act: Time Based Rate Programs. Available online: https://www.smartgrid.gov/recovery_act/time_ based_rate_programs.html (accessed on 2 January 2021). 
12. Moyo, C.; Mafuratidz, F.; Mbudzi, J.C. Demand side management (DSM) as a strategy to alleviate power shortages. Transportation 2012, 37, 885 .

13. Akinbulire, T.O.; Oluseyi, P.O.; Babatunde, O.M. Techno-economic and environmental evaluation of demand side management techniques for rural electrification in Ibadan, Nigeria. Int. J. Energy Environ. Eng. 2014, 5, 375-385. [CrossRef]

14. Khan, I. Energy-saving behaviour as a demand-side management strategy in the developing world: The case of Bangladesh. Int. J. Energy Environ. Eng. 2019, 10, 493-510. [CrossRef]

15. Barnier, V.; Boursier, S.; Holzigel, J.; Kamali, J.; Majumder, D.; Peterschmidt, N.; Browne, C.; Nderitu, D.; Bharadwaj, A.; Weston, P.; et al. Demand Side Management for Mini-Grids. Available online: https://energy4impact.org/demand-side-managementmini-grids-0?gclid=Cj0KCQiAnaeNBhCUARIsABEee8XKD35nYMBbUaBdWFyh3_VTMzqn4ztxu9_zoXoUL3xyHCTjENq3ZMaAitXEALw_wcB (accessed on 31 January 2020).

16. Yilmaz, S.; Rinaldi, A.; Patel, M.K. DSM interactions: What is the impact of appliance energy efficiency measures on the demand response (peak load management)? Energy Policy 2020, 139, 7-8. [CrossRef]

17. Nguyen, V.L.; Tran-Quoc, T.; Bacha, S.; Luu, N.A. Charging strategies to minimize the energy cost for an electric vehicle fleet. In Proceedings of the IEEE PES Innovative Smart Grid Technologies, Istanbul, Turkey, 12-15 October 2014; pp. 1-7.

18. Habib, S.; Khan, M.M.; Abbas, F.; Sang, L.; Shahid, M.U.; Tang, H. A comprehensive study of implemented international standards, technical challenges, impacts and prospects for electric vehicles. IEEE Access 2018, 6, 13866-13890. [CrossRef]

19. Kang, T.; Chae, B.; Suh, Y. Control algorithm of bi-directional power flow rapid charging system for electric vehicle using li-ion polymer battery. In Proceedings of the 2013 IEEE ECCE Asia Downunder; pp. 499-505. Available online: https://ieeexplore.ieee. org/document/ 6579143 (accessed on 15 December 2021).

20. Battery University. BU-402: What Is C-rate?-Battery University. Available online: https:/ / batteryuniversity.com/article/bu-402what-is-c-rate (accessed on 24 August 2021).

21. Battery University. BU-409: Charging Lithium-Ion-Battery University. Available online: https://batteryuniversity.com/article/ bu-409-charging-lithium-ion (accessed on 15 December 2021).

22. RMastervolt. Charging Batteries. Available online: https://www.mastervolt.com/charging-batteries/ (accessed on 15 December 2021).

23. OpenDSS. OpenDSS. Available online: https:/ / sourceforge.net/projects/electricdss / (accessed on 23 June 2020).

24. McKenna, E.; Thomson, M. High-resolution stochastic integrated thermal-electrical domestic demand model. Appl. Energy 2016, 165, 445-461. [CrossRef]

25. Leach, M.; Mullen, C.; Lee, J.; Soltowski, B.; Wade, N.; Galloway, S.; Coley, W.; Keddar, S.; Scott, N.; Batchelor, S. Modelling the Costs and Benefits of Moving to Modern Energy Cooking Services-Methods \& Application to Three Case Studies. MECS. 2021. Available online: https:/ / mecs.org.uk/publications/modelling-the-costs-and-benefits-of-moving-to-modern-energy-cookingservices-methods-application-to-three-case-studies / (accessed on 15 December 2021).

26. Leach, M.; Oduro, R. Preliminary Design and Analysis of a Proposed Solar and Battery Electric Cooking Concept: Costs and Pricing. 2015; Evidence on Demand (Prepared at the Request of the UK Department for International Development). Available online: https: / / www.gov.uk/research-for-development-outputs/preliminary-design-and-analysis-of-a-proposed-solar-andbattery-electric-cooking-concept-costs-and-pricing (accessed on 15 December 2021).

27. Kostopoulos, E.D.; Spyropoulos, G.C.; Kaldellis, J.K. Real-world study for the optimal charging of electric vehicles. Energy Rep. 2020, 6, 418-426. [CrossRef]

28. Louie, H. Off-Grid Electrical Systems in Developing Countries; Springer: Cham, Switzerland, 2018.

29. Williams, N.J.; Jaramillo, P.; Cornell, B.; Lyons-Galante, I.; Wynn, E. Load characteristics of East African microgrids. In Proceedings of the 2017 IEEE PES PowerAfrica, Accra, Ghana, 27-30 June 2017; pp. 236-241.

30. Ul-Haq, A.; Cecati, C.; Strunz, K.; Abbasi, E. Impact of electric vehicle charging on voltage unbalance in an urban distribution network. Intell. Ind. Syst. 2015, 1, 51-60. [CrossRef]

31. Energy Sector Management Assistance Program (ESMAP). Cooking with Electricity: A Cost Perspective; World Bank: Washington, DC, USA, 2020. 